\title{
Synergistic angular and spectral estimation of aerosol properties using CHRIS/PROBA-1 and simulated Sentinel-3 data
}

\author{
W. H. Davies and P. R. J. North \\ College of Science, Swansea University, Singleton Park, Swansea, SA2 8PP, UK \\ Correspondence to: W. H. Davies (w.h.davies@uclmail.net)
}

Received: 25 April 2014 - Published in Atmos. Meas. Tech. Discuss.: 3 June 2014

Revised: 4 March 2015 - Accepted: 11 March 2015 - Published: 10 April 2015

\begin{abstract}
We develop a method to derive aerosol properties over land surfaces using combined spectral and angular information, such as available from ESA Sentinel-3 mission, to be launched in 2015. A method of estimating aerosol optical depth (AOD) using only angular retrieval has previously been demonstrated on data from the ENVISAT and PROBA1 satellite instruments, and is extended here to the synergistic spectral and angular sampling of Sentinel-3. The method aims to improve the estimation of AOD, and to explore the estimation of fine mode fraction (FMF) and single scattering albedo (SSA) over land surfaces by inversion of a coupled surface/atmosphere radiative transfer model. The surface model includes a general physical model of angular and spectral surface reflectance. An iterative process is used to determine the optimum value of the aerosol properties providing the best fit of the corrected reflectance values to the physical model. The method is tested using hyperspectral, multi-angle Compact High Resolution Imaging Spectrometer (CHRIS) images. The values obtained from these CHRIS observations are validated using ground-based sun photometer measurements. Results from 22 image sets using the synergistic retrieval and improved aerosol models show an RMSE of 0.06 in AOD, reduced to 0.03 over vegetated targets.
\end{abstract}

\section{Introduction}

Limited understanding of atmospheric aerosol composition, distribution and function contributes the largest uncertainty to current estimates of radiative forcing (RF) and thereby to the uncertainty in future climate predictions (IPCC, 2013). The World Meteorological Organization (WMO) established the Global Climate Observing System (GCOS) in 1992 to fo- cus on satellite observations in order to provide better aerosol products leading to a reduction in climate uncertainty. GCOS has a target accuracy of 0.01 for aerosol optical depth (AOD) and 0.02 for single scattering albedo (SSA) (GCOS, 2006). In this paper we aim to use recent improvements in the definition of common aerosol components (Holzer-Popp et al., 2013) to show that better atmospherically corrected surface reflectance and AOD should be possible using synergistic retrieval from new satellite observations.

In summarising the drivers of climate change, the Intergovernmental Panel on Climate Change (IPCC) found that there is a negative $\mathrm{RF}$ from most aerosols with a total aerosol effect of between -1.9 and $-0.1 \mathrm{~W} \mathrm{~m}^{-2}$ (IPCC, 2013). However, the effect of aerosols is highly variable - scattering from aerosols with low absorption results in a cooling or negative forcing, whereas absorbing aerosols give a net warming or positive forcing effect (Bergstrom et al., 2002; Dubovik et al., 2002). In addition to the direct effect, aerosol also impacts cloud formation and duration. For example, the INDOEX experiment demonstrated that solar absorption by aerosols reduced day time cloud coverage over the Indian Ocean (Ackerman et al., 2000). Estimation of surface reflectance to enable determination of parameters such as albedo, also requires correction of scattering and absorption by aerosol and gases; the chief uncertainty for most shortwave channels is due to aerosol scattering (Vermote et al., 1997a). Recent reviews of retrieval of aerosol properties from existing satellites are found in Kokhanovsky and DeLeeuw (2009), Kokhanovsky et al. (2010), de Leeuw et al. (2013) and Holzer-Popp et al. (2013).

As part of the European Commission Copernicus programme, the European Space Agency (ESA) is expected to launch the first of two Sentinel-3 satellites before the end 


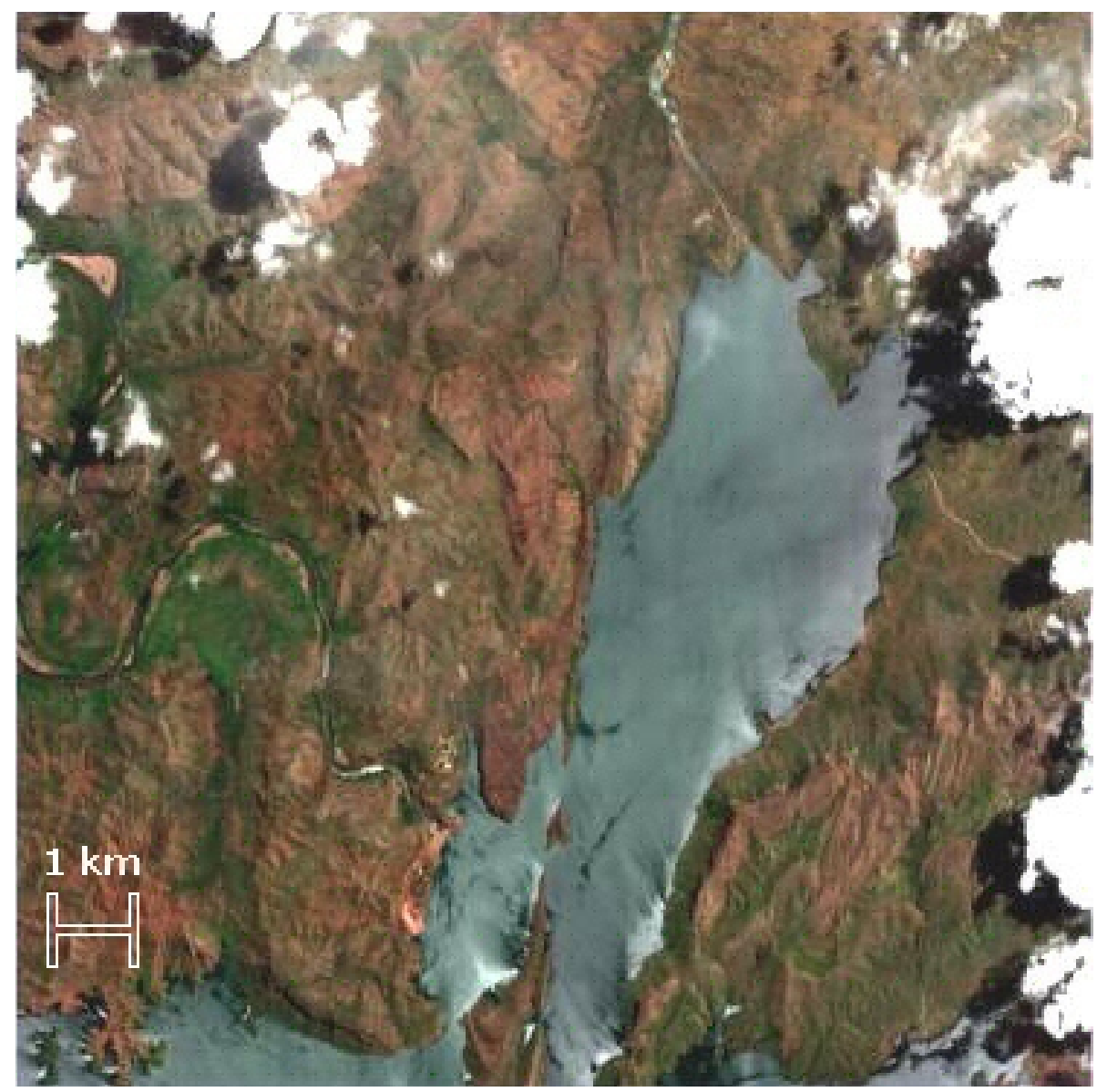

Figure 1. True colour nadir CHRIS image of lg3e35, Lake Argyle, Australia. $16.11^{\circ} \mathrm{S}, 128.75^{\circ} \mathrm{E}$ (@ Surrey Satellite Technology Ltd).

of 2015 (ESA-Earth-Online, 2014). The Sea and Land Surface Temperature Radiometer (SLSTR) and Ocean and Land Colour Instrument (OLCI) on Sentinel-3 are an improvement on the Advanced Along Track Scanning Radiometer (AATSR) and the Medium Resolution Imaging Spectrometer (MERIS) on the ENVISAT satellite with better spatial resolution, wider swath coverage and more bands (Donlon et al., 2012). A multi-angle method of retrieving surface reflectance has previously been demonstrated on data from the CHRIS and AATSR satellite instruments (North, 2002; Bevan et al., 2012; Davies et al., 2010), and has been extended to use synergistic spectral and angular information from MERIS and AATSR on ENVISAT (North et al., 2008, 2010), and OLCI and SLSTR on Sentinel-3 (North and Heckel, 2012).

Here we develop and test an experimental method for improving the estimation of AOD, and exploring the estimation of fine mode fraction (FMF) and SSA from simulated Sentinel-3 and real CHRIS data. The method explores the synergistic use of both SLSTR and OLCI using the multiangle method and a spectral method respectively to provide more constraints for the retrieval (North et al., 2008). The method is tested using the $6 \mathrm{~S}$ radiative transfer model (Ver- mote et al., 1997a) to generate simulated Sentinel-3 top-ofatmosphere (TOA) radiances. Real CHRIS data are used to simulate Sentinel-3 data, and ground-based sun photometer measurements are used to validate the method. Unless stated otherwise, all AOD values are at $0.55 \mu \mathrm{m}$ and all SSA values are at $0.87 \mu \mathrm{m}$.

\section{Satellite instruments}

\subsection{SLSTR/Sentinel-3}

Like AATSR, SLSTR is a dual-angle instrument with a nadir view and an oblique view at an angle of approximately $55^{\circ}$ through the atmosphere. However, on SLSTR the oblique view is to the rear to allow both SLSTR and OLCI to have a clear view to the sun for calibration purposes. It has a nadir swath of $1400 \mathrm{~km}$ and a dual view swath of $740 \mathrm{~km}$. There is an improved spatial resolution of $500 \mathrm{~m}$ in the visible and short-wave infrared (SWIR) channels and an additional band useful for aerosol retrieval centred at $2.25 \mu \mathrm{m}$. There is also an additional channel centred at $1.375 \mu \mathrm{m}$ but this is excluded in the aerosol retrieval because of atmospheric absorption by 
Table 1. Wavelength bands used ( $\mu \mathrm{m})$ (Donlon et al., 2012; Cutter, 2005).

\begin{tabular}{|c|c|c|c|}
\hline SLSTR & OLCI & CHRIS Mode 1 & CHRIS Mode 5 \\
\hline & 0.39250 .4075 & & \\
\hline & 0.40750 .4175 & 0.4060 .415 & \\
\hline & 0.43750 .4475 & 0.4380 .447 & 0.4380 .447 \\
\hline & 0.4850 .495 & 0.4860 .495 & 0.4860 .495 \\
\hline & & 0.4950 .505 & \\
\hline & 0.5050 .515 & 0.5050 .515 & \\
\hline & & & 0.5260 .534 \\
\hline \multirow[t]{5}{*}{0.5400 .560} & 0.5550 .565 & 0.5560 .566 & 0.5460 .556 \\
\hline & & & 0.5660 .573 \\
\hline & 0.6150 .625 & 0.6180 .627 & \\
\hline & & & 0.6270 .636 \\
\hline & 0.6600 .670 & 0.6560 .666 & 0.6560 .666 \\
\hline \multirow[t]{6}{*}{0.6550 .675} & 0.6700 .6775 & 0.6660 .677 & 0.6660 .677 \\
\hline & 0.67750 .685 & 0.6770 .683 & 0.6770 .689 \\
\hline & 0.703750 .71375 & 0.7060 .712 & 0.7060 .712 \\
\hline & 0.7500 .7575 & 0.7520 .759 & 0.7520 .759 \\
\hline & 0.7600 .7625 & 0.7590 .766 & 0.7590 .766 \\
\hline & 0.771250 .78625 & 0.7730 .781 & 0.7730 .788 \\
\hline \multirow[t]{5}{*}{0.8550 .875} & 0.8550 .875 & 0.8630 .872 & 0.8630 .881 \\
\hline & 0.8800 .890 & 0.8810 .891 & 0.8810 .891 \\
\hline & 0.8950 .905 & 0.9000 .910 & 0.9000 .910 \\
\hline & & 0.9810 .992 & 0.9810 .992 \\
\hline & 1.0001 .040 & & 1.0031 .036 \\
\hline 1.5801 .640 & & & \\
\hline 2.2252 .275 & & & \\
\hline
\end{tabular}

water vapour. The five bands used are listed in Table 1. Scanner calibration using black body cavities is performed every second scan and visible channel gain calibration is performed once per orbit (Donlon et al., 2012).

\subsection{OLCI/Sentinel-3}

OLCI is a push-broom instrument with 21 spectral channels covering the same range as MERIS with a spatial resolution of $300 \mathrm{~m}$. Only 18 bands are used in the retrieval - the bands centred at the following wavelengths are excluded because of atmospheric absorption: 764.375, 767.5 and $940 \mathrm{~nm}$. The bands used are listed in Table 1. There is an improved global coverage compared to MERIS of less than 4 days over ocean and less than 3 days over land (assuming only 1 satellite). The swath of $1270 \mathrm{~km}$ overlaps with SLSTR which facilitates synergistic retrieval and is tilted westwards to mitigate contamination from sun-glint. Calibration is performed at the southern terminator crossing with dark current calibration and radiometric calibration in the first orbit in sequence and then in the following orbit dark current calibration and spectral calibration (Donlon et al., 2012).

\subsection{CHRIS/PROBA-1}

CHRIS is a multi-angle instrument which acquires images at a high spatial resolution (17 or $34 \mathrm{~m}$ ), and is a hyper-spectral instrument offering a subset of 18 to 62 spectral bands in the optical region between 400 and $1050 \mathrm{~nm}$. CHRIS acquires up to five images of the target area with a swath width of $13 \mathrm{~km}$. The viewing zenith angles are nominally given as $55^{\circ}$ and $36^{\circ}$ in the backwards and forwards direction, and at nadir. There are a range of modes of data that can be selected for specific applications (Davies et al., 2010). In this data set, only modes 1 and 5 are used - mode 5 for the Gilching site and mode 1 for all the other target sites. The 18 bands used are listed in Table 1.

Measurements from the CHRIS instrument have a number of sources of uncertainty. One source of uncertainty is due to incomplete knowledge of the pointing of CHRIS to the target, which leads to the images being misaligned (Davidson and Vuilleumier, 2004). Radiometric uncertainties for this push-broom instrument come from the response of the charge coupled device (CCD), the telescope and the spectrometer, and are discussed in Gómez-Chova et al. (2008) and Cutter and Lobb (2004). An example CHRIS image over Lake Argyle, Australia is displayed in Fig. 1. 
Table 2. Parameters describing the aerosol components (de Leeuw et al., 2013).

\begin{tabular}{lllll}
\hline $\begin{array}{l}\text { Aerosol } \\
\text { component }\end{array}$ & $\begin{array}{l}\text { Real index of } \\
\text { refraction } \\
(0.55 \mu \mathrm{m})\end{array}$ & $\begin{array}{l}\text { Imaginary } \\
\text { index of } \\
\text { refraction } \\
(0.55 \mu \mathrm{m})\end{array}$ & $\begin{array}{l}\text { Effective } \\
\text { radius } \\
(\mu \mathrm{m})\end{array}$ & $\begin{array}{l}\text { Geometric } \\
\text { standard } \\
\text { deviation }\end{array}$ \\
\hline Dust & 1.56 & 0.0018 & 1.94 & 1.822 \\
Sea salt & 1.4 & 0 & 1.94 & 1.822 \\
Weakly absorbing & 1.4 & 0.003 & 0.14 & 1.7 \\
Strongly absorbing & 1.5 & 0.040 & 0.14 & 1.7 \\
\hline
\end{tabular}

\section{Retrieval method}

\subsection{Overview}

The retrieval is an iterative process: (1) the TOA Radiance measurements are transformed using 6S (Vermote et al., 1997a), along with an estimated value for the aerosol properties, to estimate surface reflectance; (2) an error metric is calculated based on fit of this surface reflectance set $\left(R_{\text {surf }}\right)$ to a model of idealised land surface angular and spectral variation; (3) the aerosol estimate is refined, and steps 1 and 2 repeated until convergence, based on minimisation of the error metric.

\subsection{Multi-angle model}

The model - Eq. (1) - calculates $R_{\text {ang }}$, the surface reflectance by the multi-angle method. This model is developed and justified in North et al. (1999) and a summary is provided here. This model has been applied to the (A)ATSR series of dualangle instruments, giving accurate retrieval over a range of surfaces (Bevan et al., 2012). The bidirectional reflectance distribution function (BRDF) of the land surface varies with wavelength and with viewing angle. Studies have shown that there is a similarity in the angular variation of the BRDF across wavelengths, that there is a change of brightness with view angle, but the colour remains predominantly the same (North et al., 1999). The BRDF is determined by the optical and geometric properties of the surface. Significant contributors are multiple scattering and the variation in scattering with view direction. Thus we define an aggregated single scattering phase function parameter $P\left(\theta_{\mathrm{v}}\right)$ that is dependent on view angle but independent of wavelength, and a Lambertian scattering albedo parameter $\omega(\lambda)$ that is only dependent on wavelength. In order to solve these unknown parameters the inversion requires a minimum of two view angles, and a minimum of two wavelengths, but may be applied to the full set of CHRIS viewing angles and any waveband set (Davies et al., 2010). The model calculates the reflectance as the sum of an anisotropic singly scattered component and an isotropic multiply scattered component:

$$
\begin{aligned}
& R_{\text {ang }}\left(\lambda, \theta_{\mathrm{v}}\right)=(1-D(\lambda)) P\left(\theta_{\mathrm{v}}\right) \omega(\lambda) \\
& +\frac{\gamma \omega(\lambda)}{1-g}(D(\lambda)+g(1-D(\lambda))),
\end{aligned}
$$

where

$g=(1-\gamma) \omega(\lambda)$,

where $\lambda$ is the wavelength, $\theta_{\mathrm{v}}$ the view direction, $\omega(\lambda)$ the Lambertian scattering albedo, $P\left(\theta_{\mathrm{v}}\right)$ the aggregate single scattering phase function, $D(\lambda)$ is the fraction of downwelling diffuse light and $\gamma$ represents the probability of escape from the surface without further scattering. The set of free parameters $\omega(\lambda)$ and $P\left(\theta_{\mathrm{v}}\right)$ are found by inversion. Comparison with a large data set of natural surface reflectances shows that a fixed value of $\gamma=0.3$ is adequate to characterize land surface scattering for the inversion (North et al., 1999). $D(\lambda)$ is an output from the radiative transfer (RT) calculations (Davies et al., 2010).

\subsection{Spectral model}

Here we extend the method to make use of spectral information in addition to angular. For single angle viewing we use a spectral signature to isolate the aerosol scattering from the surface reflectance. We use the channels in the blue spectral region for aerosol retrieval and the near-infrared (NIR) channels to estimate the surface properties (von HoyningenHuene et al., 2011). For this reason, in order to retrieve AOD, a higher weighting is given to the shortest wavelength. We identify a set of surfaces with known reflectance and assuming an atmospheric profile, we fit the atmospherically corrected surface reflectance with the assumed target reflectance. Similar approaches have been used in aerosol retrieval for CHRIS (Guanter et al., 2005) and for MERIS (North et al., 2008; von Hoyningen-Huene et al., 2011).

The limitation of using vegetation and soil spectra in this approach is that it is only generally suitable for dark surfaces with relatively low spectral variability and has been found to produce high error with bright arid surfaces. However, here we explore the use of a variety of vegetation and arid spectra (see Tables 3 and 4 ) in order to improve the retrieval. 
Table 3. OLCI values of end member spectra used for spectral mixing model (Baldridge et al., 2009; Vermote et al., 1997a).

\begin{tabular}{lccccc}
\hline $\begin{array}{l}\text { Wavelength } \\
(\mu \mathrm{m})\end{array}$ & $\rho_{\mathrm{vg}}$ & $\rho_{\mathrm{vd}}$ & $\rho_{\mathrm{vo}}$ & $\rho_{\mathrm{S}}$ & $\rho_{\mathrm{a}}$ \\
\hline 0.400000 & 0.046470 & 0.157013 & 0.045815 & 0.036768 & 0.029020 \\
0.412500 & 0.047242 & 0.170558 & 0.063035 & 0.049469 & 0.038720 \\
0.442500 & 0.049020 & 0.199196 & 0.076099 & 0.073796 & 0.062344 \\
0.490000 & 0.052483 & 0.241431 & 0.106535 & 0.107402 & 0.103530 \\
0.510000 & 0.064435 & 0.259522 & 0.121465 & 0.122475 & 0.123760 \\
0.560000 & 0.103197 & 0.313778 & 0.121022 & 0.182937 & 0.194380 \\
0.620000 & 0.061505 & 0.372506 & 0.077998 & 0.254738 & 0.267570 \\
0.665000 & 0.045183 & 0.419670 & 0.104285 & 0.283098 & 0.289420 \\
0.673750 & 0.044693 & 0.430844 & 0.161134 & 0.287909 & 0.300673 \\
0.681250 & 0.047156 & 0.440263 & 0.206083 & 0.294213 & 0.299675 \\
0.708750 & 0.176344 & 0.471079 & 0.377132 & 0.310058 & 0.321040 \\
0.753750 & 0.482001 & 0.510188 & 0.519670 & 0.334321 & 0.336595 \\
0.761250 & 0.492245 & 0.515876 & 0.520708 & 0.336472 & 0.337490 \\
0.778750 & 0.503628 & 0.525009 & 0.523003 & 0.345266 & 0.343143 \\
0.865000 & 0.523376 & 0.575062 & 0.529749 & 0.361608 & 0.348803 \\
0.885000 & 0.525212 & 0.585798 & 0.530996 & 0.365007 & 0.352213 \\
0.900000 & 0.525729 & 0.594547 & 0.532001 & 0.367217 & 0.351690 \\
1.020000 & 0.518955 & 0.637942 & 0.530199 & 0.397384 & 0.378390 \\
\hline
\end{tabular}

The assumed surface reflectance of the target is represented as a linear mixture of a set of spectra:

$$
\begin{aligned}
& R_{\mathrm{spec}}(\lambda)=c_{\mathrm{vg}} \rho_{\mathrm{vg}}(\lambda)+c_{\mathrm{vd}} \rho_{\mathrm{vd}}(\lambda)+c_{\mathrm{vo}} \rho_{\mathrm{vo}}(\lambda) \\
& +c_{\mathrm{s}} \rho_{\mathrm{s}}(\lambda)+c_{\mathrm{a}} \rho_{\mathrm{a}}(\lambda)
\end{aligned}
$$

where $c_{\mathrm{vg}}$ is the fractional coverage of green vegetation and $\rho_{\mathrm{vg}}$ is the corresponding surface reflectance of the input spectra and is a function of wavelength. Similarly, $c_{\mathrm{vd}}$ and $\rho_{\mathrm{vd}}$ are the fractional coverage and spectra for dry grass, $c_{\mathrm{vo}}$ and $\rho_{\mathrm{vo}}$ for other vegetation, $c_{\mathrm{s}}$ and $\rho_{\mathrm{s}}$ for soil and $c_{\mathrm{a}}$ and $\rho_{\mathrm{a}}$ for arid soil (Baldridge et al., 2009; Vermote et al., 1997a). The OLCI spectra are listed in Table 3 , and CHRIS spectra in Table 4.

The metric for the single-angle spectral retrieval is given by

$E_{\mathrm{spec}}=\frac{\sum_{\lambda=1}^{18} w_{\lambda}\left[R_{\mathrm{surf}}(\lambda)-R_{\mathrm{spec}}(\lambda)\right]^{2}}{\sum_{\lambda=1}^{18} w_{\lambda}}$,

where $\lambda$ is the wavelength and $w_{\lambda}$ is the per-band weighting factor. The per-band weighting factor values are normalised according to Eq. (4). By experiment, lowest error was found with a weighting of $1.5 / 18$ for the first wavelength, and a compensating $0.5 / 18$ for the last (infrared) wavelength, and unity for all other wavelengths:

$\sum_{\lambda=1}^{18} w_{\lambda}=1$

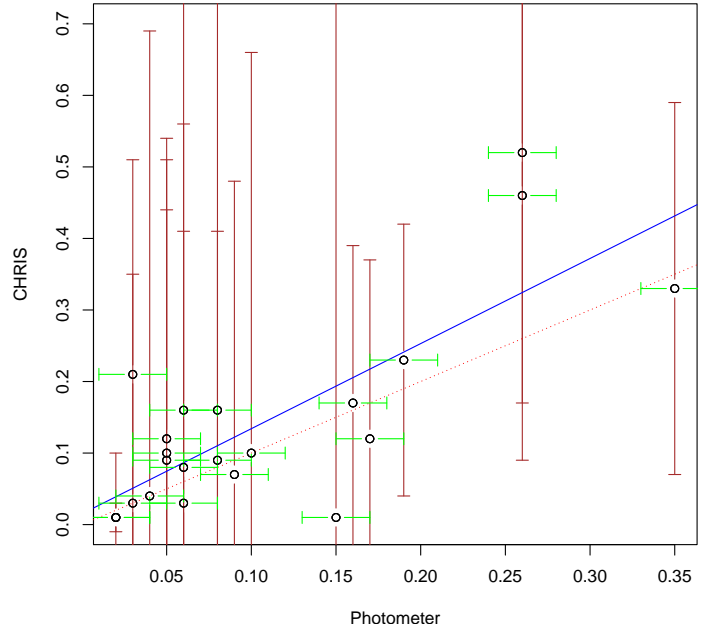

Figure 2. AOD estimated using original method Davies et al. (2010), compared with sun photometer data over 22 CHRIS image sets.

\subsection{Surface reflectance estimation}

The estimated surface reflectance $\left(R_{\text {surf }}\right)$ is calculated from the TOA radiance measurements at each iteration using a look-up table (LUT) of coefficients determined by $6 \mathrm{~S}$, and using aerosol properties determined under the ESA Aerosol CCI definitions (de Leeuw et al., 2013). 
Table 4. Values of end member spectra used for spectral mixing model at CHRIS wavebands (Baldridge et al., 2009; Vermote et al., 1997a).

\begin{tabular}{lccccc}
\hline $\begin{array}{l}\text { Wavelength } \\
(\mu \mathrm{m})\end{array}$ & $\rho_{\mathrm{vg}}$ & $\rho_{\mathrm{vd}}$ & $\rho_{\mathrm{vo}}$ & $\rho_{\mathrm{s}}$ & $\rho_{\mathrm{a}}$ \\
\hline 0.410500 & 0.047118 & 0.168391 & 0.062435 & 0.047437 & 0.035117 \\
0.442000 & 0.048990 & 0.198719 & 0.075873 & 0.073391 & 0.062389 \\
0.490000 & 0.052483 & 0.241431 & 0.106638 & 0.107402 & 0.103530 \\
0.500000 & 0.058459 & 0.250477 & 0.114682 & 0.114938 & 0.115380 \\
0.510000 & 0.064435 & 0.259522 & 0.121645 & 0.122475 & 0.123760 \\
0.561000 & 0.102502 & 0.314757 & 0.120774 & 0.184134 & 0.194920 \\
0.622000 & 0.060780 & 0.374602 & 0.077075 & 0.255998 & 0.265680 \\
0.661000 & 0.046634 & 0.415478 & 0.083445 & 0.280577 & 0.290130 \\
0.672000 & 0.044791 & 0.428609 & 0.143919 & 0.286947 & 0.294930 \\
0.680000 & 0.046746 & 0.438693 & 0.198597 & 0.293162 & 0.298620 \\
0.709000 & 0.178042 & 0.471296 & 0.371412 & 0.310193 & 0.318970 \\
0.755500 & 0.484391 & 0.511515 & 0.520058 & 0.334823 & 0.336180 \\
0.762500 & 0.493058 & 0.516031 & 0.521425 & 0.337100 & 0.338945 \\
0.777000 & 0.502490 & 0.523939 & 0.521732 & 0.344387 & 0.344520 \\
0.867500 & 0.523605 & 0.576404 & 0.530533 & 0.362033 & 0.348741 \\
0.886000 & 0.525246 & 0.586381 & 0.531138 & 0.365154 & 0.352515 \\
0.905000 & 0.525447 & 0.597530 & 0.531993 & 0.368474 & 0.353335 \\
0.986500 & 0.518940 & 0.629763 & 0.536559 & 0.388962 & 0.367166 \\
\hline
\end{tabular}

The atmospheric correction problem is solved by $6 \mathrm{~S}$ using

$$
\begin{aligned}
& \rho_{\mathrm{TOA}}^{i=1,3}\left(\theta_{s}, \theta_{v}, \phi_{s}-\phi_{v}\right)=T_{g}^{\mathrm{OG}}\left(\theta_{s}, \theta_{v}\right)\left[\rho_{\mathrm{R}}\right. \\
& +\left(\rho_{\mathrm{R}+\mathrm{A}}-\rho_{\mathrm{R}}\right) T_{g}^{\mathrm{H}_{2} \mathrm{O}}\left(\theta_{s}, \theta_{v}, \frac{i-1}{2} U_{\mathrm{H}_{2} \mathrm{O}}\right) \\
& \left.+T^{\downarrow}\left(\theta_{s}\right) T^{\uparrow}\left(\theta_{v}\right) \frac{\rho_{s}}{1-S \rho_{s}} T_{g}^{\mathrm{H}_{2} \mathrm{O}}\left(\theta_{s}, \theta_{v}, U_{\mathrm{H}_{2} \mathrm{O}}\right)\right],
\end{aligned}
$$

where the TOA reflectance $\left(\rho_{\mathrm{TOA}}\right)$ is dependent on the solar zenith $\left(\theta_{S}\right)$ and solar azimuth angles $\left(\phi_{S}\right)$ and the view zenith $\left(\theta_{v}\right)$ and view azimuth angles $\left(\phi_{v}\right) . i=1$ represents the minimum absorption where the water vapour is under the aerosol layer, $i=3$ represents the maximum absorption where the water vapour is above the aerosol layer and $i=2$ represents the case where half of the water vapour present absorbs the aerosol path radiance. $T_{g}^{\mathrm{OG}}$ represents the gaseous transmission for gases other than water vapour. $\rho_{\mathrm{R}}$ is the molecular reflectance. $\rho_{\mathrm{A}}$ is the aerosol reflectance. $T_{g}^{\mathrm{H}_{2} \mathrm{O}}$ refers to $\mathrm{H}_{2} \mathrm{O}$ absorption. $T^{\downarrow}$ is the total transmission of the atmosphere on the path to the surface from the sun. $T^{\uparrow}$ is the total transmission of the atmosphere on the path to the sensor from the surface. $\rho_{s}$ is the reflectance of a Lambertian homogeneous target at sea level. $S$ is the spherical albedo of the atmosphere and $U_{\mathrm{H}_{2} \mathrm{O}}$ is the water vapour content (Vermote et al., 1997b).

The original method for CHRIS retrieval (Davies et al., 2010) retrieved a single unknown, AOD. Here we develop the method to retrieve four unknowns: AOD at a reference wavelength $(0.55 \mu \mathrm{m})$ and three components of aerosol mixture (the fourth component is implicit since all four must sum to $100 \%)$. The four components are non-spherical dust, sea salt, weakly absorbing and strongly absorbing aerosol (de Leeuw et al., 2013). A full grid of AOD and mixture values in steps

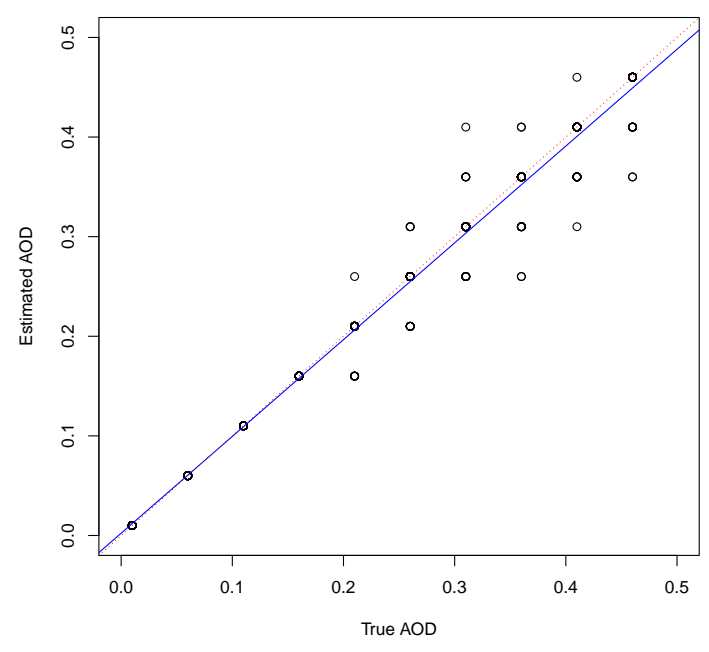

Figure 3. AOD comparison for synergistic retrieval from simulated SLSTR and OLCI data.

of $20 \%$ is used in a LUT-based approach giving a total of 560 points. The log-normal parameters and their associated midvisible indices of refraction are listed in Table 2 . Ten values of AOD are used from 0.01 to 0.46 in intervals of 0.05 - the range has been chosen to enclose that from the CHRIS data set. The retrieval process iterates through all the values in the grid, and the AOD/mix with the best fit is the solution.

For the CHRIS multi-angle viewing, the least-squares method is modified in order to take account of the need to propagate the uncertainties through to the resulting estimates. The approach of Diner et al. (2008) is adopted for the modified error metric which is given by Eq. (6). 
Table 5. CHRIS sites and image sets.

\begin{tabular}{lcllcc}
\hline Site & Sets & Land cover & Model & Date range & AOD range \\
\hline Tinga Tingana (Aus) & 8 & Arid & Desertic & Dec 2003-Nov 2006 & $0.02-0.10$ \\
Lake Argyle (Aus) & 8 & Semi-arid & Continental & Jun 2003-Apr 2007 & $0.02-0.35$ \\
Great Plains (USA) & 2 & Agricultural & Continental & Oct 2003-May 2004 & $0.03-0.08$ \\
Mexico City (Mex) & 2 & Urban & Urban & Nov 2003-Dec 2003 & 0.26 \\
Lanai (USA) & 1 & Shrublands & Maritime & Nov 2003 & 0.06 \\
Gilching (Ger) & 1 & Agricultural & Continental & May 2004 & 0.16 \\
\hline
\end{tabular}

Table 6. Results from simulated data.

\begin{tabular}{lccccc}
\hline Property & Fig. & RMSE & $r^{2}$ & Slope & Offset \\
\hline AOD & 3 & 0.03 & 0.97 & 0.97 & 0.002 \\
FMF & 4 & 0.11 & 0.86 & 0.93 & 0.04 \\
SSA & 5 & 0.02 & 0.77 & 0.88 & 0.11 \\
\hline
\end{tabular}

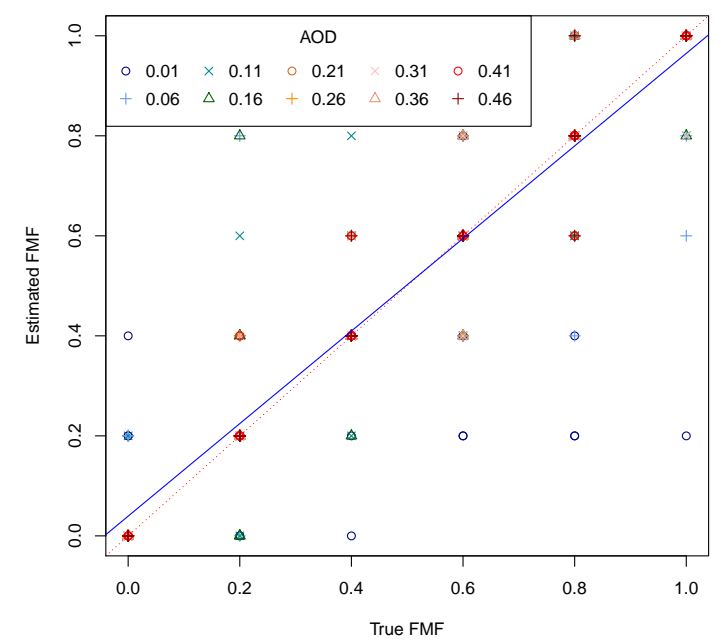

Figure 4. Simulated FMF vs. estimated FMF categorised by AOD from synergistic retrieval.

\subsection{Retrieval of surface reflectance and aerosol}

An iterative search for the optimum aerosol model and optical depth is performed, by minimising the difference between the modelled and measured surface reflectance using a metric combining the angular and spectral constraints:

$E_{\text {mod }}=E_{\text {ang }}+k E_{\text {spec }}$.

For a given aerosol model, the Powell and Brent methods (Press et al., 1992) are used to determine the parameters which minimise the constraint (6) such that $E_{\min }$ is the minimised value of $E_{\text {ang }}$ :

$E_{\text {ang }}=\sum_{\theta_{\mathrm{v}}=1}^{5} \sum_{\lambda=1}^{18} \frac{\left[R_{\text {surf }}\left(\lambda, \theta_{\mathrm{v}}\right)-R_{\text {ang }}\left(\lambda, \theta_{\mathrm{v}}\right)\right]^{2}}{\sigma_{\text {surf }}^{2}+\sigma_{\text {ang }}^{2}}$,

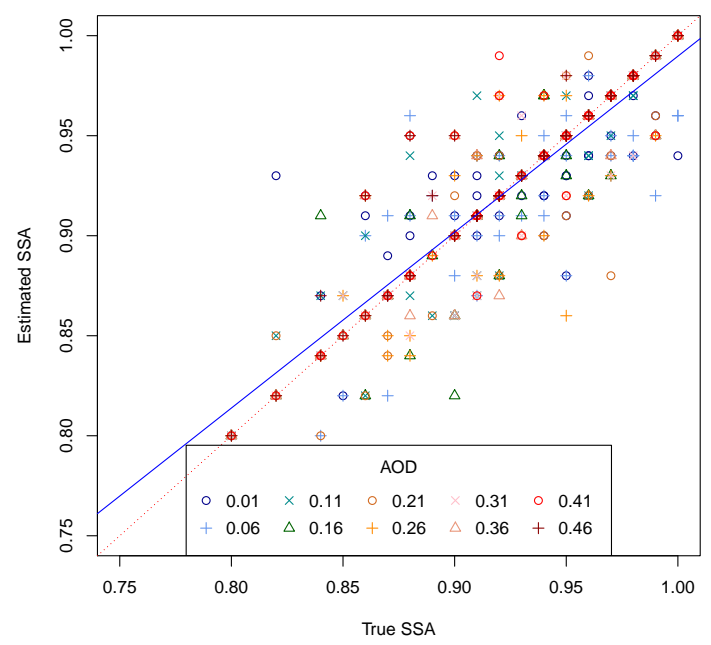

Figure 5. Simulated SSA vs. estimated SSA categorised by AOD from synergistic retrieval.

where $\lambda$ is the wavelength and $\theta_{\mathrm{v}}$ the view direction, and $\sigma_{\text {surf }}^{2}$ is the uncertainty estimate for $R_{\text {surf }}$. The error in $R_{\text {ang }}$ is characterised by using simulated data from 36 sets of conditions $\left(R_{\text {sim }}\right)$. The error variance at each view angle/wavelength combination is given by

$\sigma_{\text {ang }}^{2}=\frac{1}{n} \sum_{s=1}^{n}\left[R_{\text {sim }}\left(\lambda, \theta_{\mathrm{v}}, s\right)-R_{\text {ang }}\left(\lambda, \theta_{\mathrm{v}}, s\right)\right]^{2}$

where $n=36$, giving estimates of $\sigma_{\text {ang }}^{2}$ for each view angle/wavelength combination. For synergistic retrieval, the spectral and angular retrievals are run separately as a first iteration in order to calculate a normalising scaling factor $k$ giving equal weighting to angular and spectral metrics.

\subsection{Error estimate in AOD}

Values of the error metric $E_{\text {mod }}$ bounding the minimum value are used to compute a parabolic fit, represented by the coefficients in (Diner et al., 2008)

$\ln \left(E_{\mathrm{mod}}\right)=A+B \tau+C \tau^{2}$ 
Table 7. Results from CHRIS data.

\begin{tabular}{lllcccrrrr}
\hline Property & Source & Method & Fig. & RMSE & $r^{2}$ & Slope & Offset & CHRIS mean & Photometer mean \\
\hline AOD & All sites & Angular & 6 & 0.07 & 0.58 & 0.81 & 0.002 & 0.09 & 0.11 \\
AOD & All sites & Spectral & 8 & 0.16 & 0.00 & 0.001 & 0.13 & 0.13 & 0.11 \\
AOD & All sites & Synergistic & 10 & 0.06 & 0.65 & 0.90 & -0.008 & 0.09 & 0.11 \\
AOD & Vegetated & Angular & 7 & 0.04 & 0.86 & 1.3 & -0.03 & 0.08 & 0.09 \\
AOD & Vegetated & Spectral & 9 & 0.06 & 0.44 & 0.57 & 0.007 & 0.06 & 0.09 \\
AOD & Vegetated & Synergistic & 14 & 0.03 & 0.89 & 1.2 & -0.02 & 0.08 & 0.09 \\
FMF & All sites & Synergistic & 15 & 0.49 & 0.05 & -0.30 & 0.82 & 0.65 & 0.59 \\
SSA & All sites & Synergistic & 16 & 0.24 & 0.00 & 0.001 & 0.97 & 0.97 & 0.80 \\
\hline
\end{tabular}

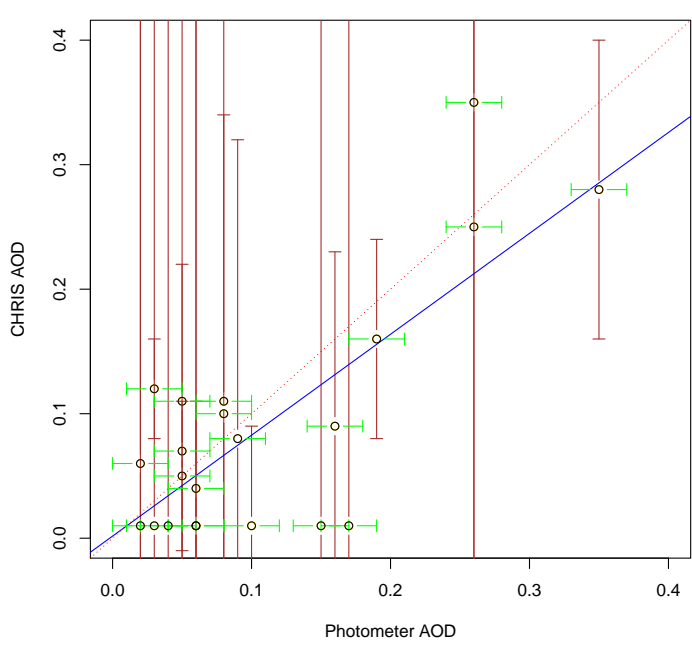

Figure 6. AOD estimated using angular constraint only, compared with sun photometer data over 22 CHRIS image sets.

and the uncertainty $\left(\sigma_{\tau}\right)$ in $\tau_{\text {best }}$ (the value of AOD that minimises $E_{\text {mod }}$ ) is given by (Diner et al., 2008)

$\sigma_{\tau}=\sqrt{\frac{\ln \left(1+\frac{1}{E_{\min }}\right)}{C} .}$

The uncertainty in the retrieved mixture is calculated using the associated SSA value. Equations (8) and (9) are used again but substituting SSA for AOD. The uncertainty values for SSA are also used for the FMF estimates calculated from the same retrieved mixture.

\section{Test data sets}

\subsection{Simulated data}

Simulated data were generated to provide an initial test of the inversion. Simulated SLSTR and OLCI TOA radiances are generated by running $6 \mathrm{~S}$ in forward mode using the 560 sets of AOD/mix, other parameters for the simulation are as follows with the geometry taken from one of the CHRIS im-

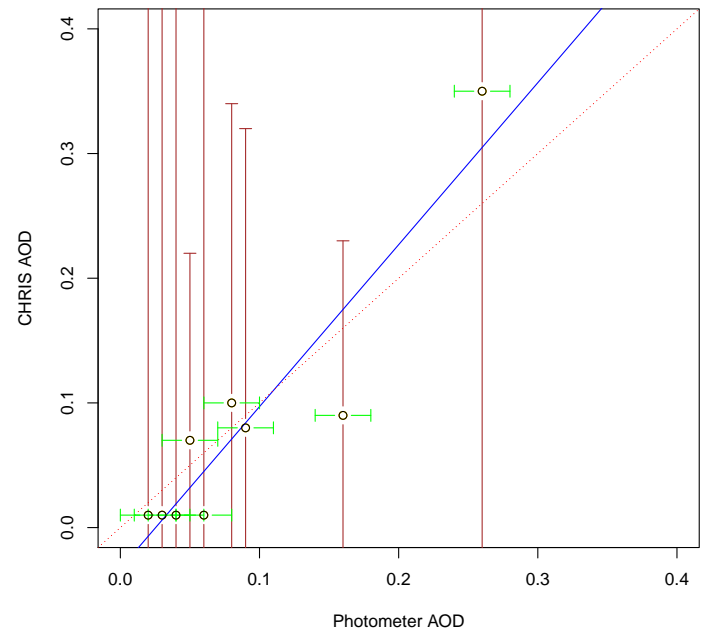

Figure 7. AOD for angular retrieval from CHRIS data for sites where the mean NDVI $>0.4$.

age sets: solar zenith angle (SZA), $15.1^{\circ}$; solar azimuth angle (SAA), $95.3^{\circ}$; view zenith angle (VZA), $7.25^{\circ}$ for nadir, and $55^{\circ}$ for the oblique view; view azimuth angle (VAA), $316.12^{\circ}$; month, 11; day, 9; atmosphere, tropical; altitude, $150 \mathrm{~m}$ and surface type, Lambertian vegetation. The bands are listed in Table 1. The AOD, FMF and SSA values from the retrieval (estimated AOD, FMF or SSA) are compared with the values from the generation of each TOA set (true AOD, FMF or SSA).

\subsection{CHRIS data}

Twenty-two image sets were used from six different sites (ESA-Archive, 2014). These are listed in Table 5 together with the number of image sets processed from that site, the type of land cover, the aerosol model used in the original method, the date range of the sets and the range of AOD as measured by the photometers (Davies et al., 2010). For analysis of results, the images are further divided into nonvegetated vs. vegetated scenes, using a threshold of mean NDVI $>0.4$ to partition the set. A subset of 18 bands from 


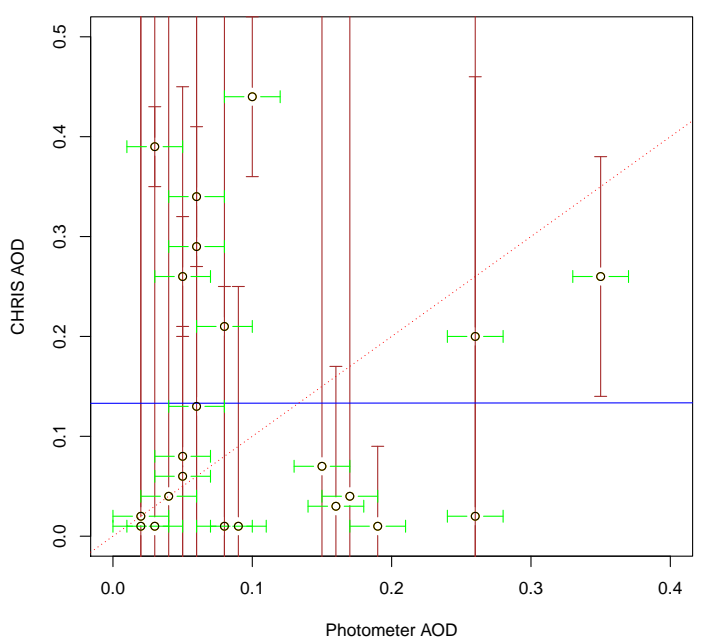

Figure 8. AOD retrieved using spectral constraint only, over 22 CHRIS image sets.

CHRIS were chosen to correspond with a subset of the bands from OLCI and SLSTR, and are listed in Table 1.

This represents all available archived CHRIS data suitable for testing. Further image sets were rejected for a variety of reasons: (i) no AERONET time/space coincidence; (ii) no acquisition of multi-angular data; (iii) no adequate meta-data for view geometry; (iv) insufficient co-registered, cloud-free pixels visible in all views; (v) the retrieval failed the $E_{\min }$ threshold test; (vi) when evaluating FMF and SSA retrieval, the AOD at $440 \mathrm{~nm}$ must be $>0.2$.

\section{Results}

\subsection{AOD from simulated data}

The AOD values retrieved from each of the 560 TOA radiance sets using the synergy method are compared with the true values in Fig. 3. The red dotted line shows the 1:1 relationship, and the blue solid line represents the fitted trend line. The RMSE between true and estimated values, the value of $r^{2}$, the regression coefficients for the slope and for the offset are listed in Table 6 together with the results for the FMF and SSA properties.

An example of retrieved surface reflectance values from one of the 560 sets is displayed in Fig. 11, following successful aerosol retrieval. The simulated reflectances generated are marked in red and the retrieved reflectances are marked in blue, shown at all OLCI and SLSTR wavelengths.

\subsection{AOD from CHRIS data}

The results from the CHRIS images were analysed for image sets where there are AOD, FMF and SSA values to validate the retrieval (22 for AOD and FMF, 19 for SSA). However since the spectral constraint does not provide information ex-

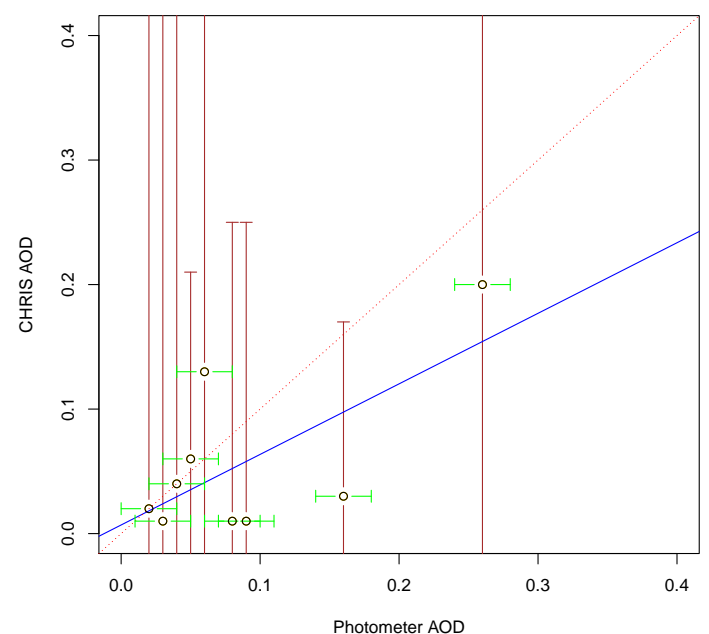

Figure 9. AOD comparison for spectral retrieval from CHRIS data where the mean NDVI $>0.4$.

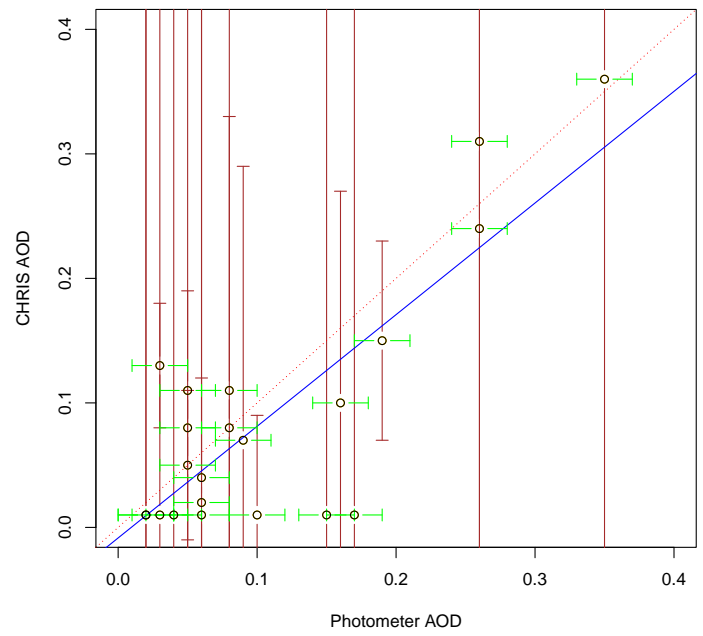

Figure 10. AOD comparison for synergistic (combined spectral and angular) retrieval from CHRIS data.

cept over at least partially vegetated surfaces, testing over a reduced set was also performed, where image sets are rejected if the mean NDVI is less than 0.4. A second set of results are displayed with nine image sets where the mean NDVI is greater than 0.4. For comparison, the AOD estimates from the original method Davies et al. (2010), which uses a version of the angular constraint only, and a standard 6S model set (Vermote et al., 1997a) are also displayed in Fig. 2.

\subsubsection{All sites}

The AOD value for each of the CHRIS image sets using only the angular method is compared with the ground-based photometer readings in Fig. 6. The RMSE between photometer and CHRIS retrievals, the value of $r^{2}$, the regression coeffi- 


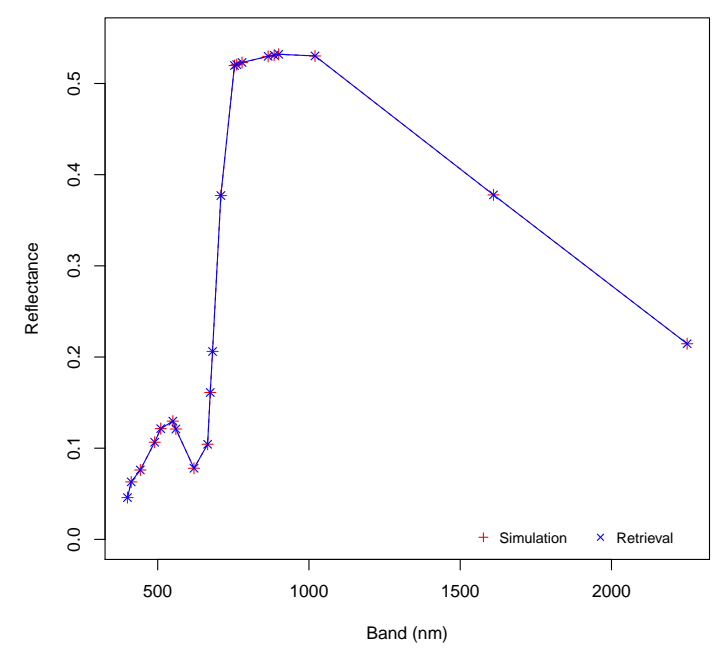

Figure 11. Retrieved nadir surface reflectance from simulated SLSTR and OLCI data, compared with spectrum used in forward simulation $(\mathrm{AOD}=0.46,100 \%$ dust $)$.

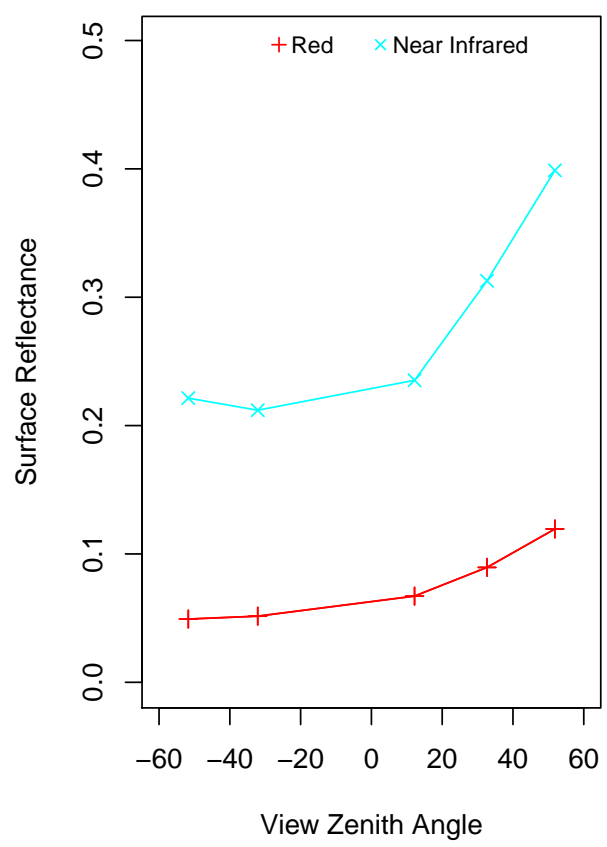

Figure 12. Retrieved multi-angle surface reflectance from CHRIS image set $\lg 41 \mathrm{c} 8$ (Lake Argyle), at red (672nm) and NIR (868nm) wavebands.

cients for the slope and for the offset, the mean AOD for the CHRIS data set and the photometer mean are listed in Table 7 together with the AOD results for the spectral and synergistic methods.

\subsubsection{Vegetated sites}

The AOD value for each of the screened CHRIS image sets where the mean NDVI is greater than 0.4 using only the an-

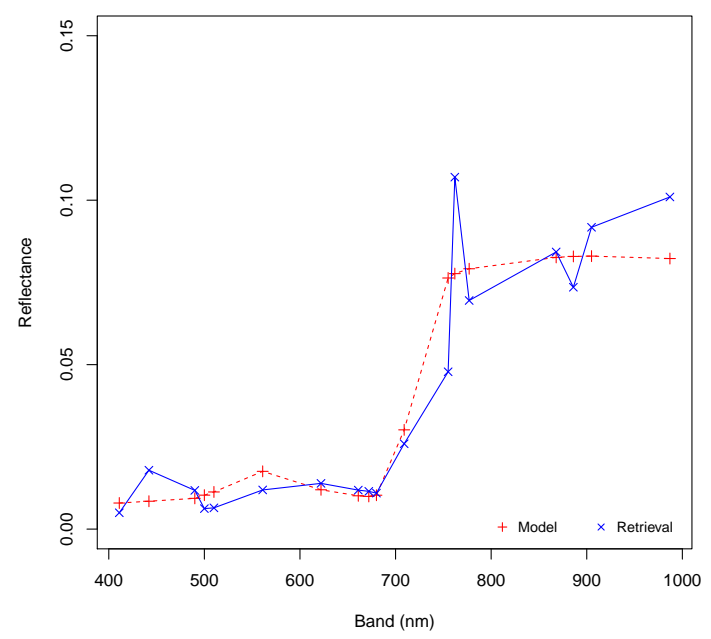

Figure 13. Retrieved spectral surface reflectance (solid line), and corresponding best fit spectral model (dashed line), derived from CHRIS image set ln3a16 (Lanai).

gular method is compared with the ground-based photometer readings in Fig. 7. Values for results from vegetated sites are listed in Table 7.

An example of the retrieved multi-angle surface reflectance values ( 672 and $868 \mathrm{~nm}$ ) from one of the image sets that passes the NDVI threshold test is shown in Fig. 12. The image set $\lg 41 \mathrm{c} 8$ was acquired over Lake Argyle, Australia on 5 June 2004. The SZA is $44^{\circ}$ and the Relative Azimuth (RA) ranges from $-153^{\circ}$ to $+9^{\circ}$. The retrieved spectral surface reflectance values (nadir view) from a second image set that passes the NDVI threshold test are displayed in Fig. 13, along with the fitted reflectance from the mixture model. The image set $\ln 3$ a16 was acquired over Lanai, Hawaii on 10 November 2003. The percentage of the various surface types in the model that gave the best fit for this region of interest (ROI) were as follows: $94 \%$ green vegetation, $4 \%$ soil and $2 \%$ dry grass. This ROI produced an overestimation of AOD (0.21 compared to an estimate of 0.06 from Aeronet). The spike visible at $760 \mathrm{~nm}$ is due to oxygen absorption, and this band is not used in the retrieval.

\subsection{FMF from CHRIS data}

The FMF value for each of the CHRIS image sets, over the full data set, calculated from the estimated mixture using the synergistic method is compared with the AERONET estimates in Fig. 15. Results for FMF retrieval are listed in Table 7. Thresholding for high NDVI and optical depth yielded only two image sets suitable for testing - the image set from Gilching (gc) with the image id 415a resulted in an estimate for the FMF as $1.0 \pm 0.13$, compared to the Aeronet estimate of $0.82 \pm 0.11$. The image set from Mexico City (mc) with id 3 ae 3 gave a retrieved estimate of $1.0 \pm 0.49$ compared to Aeronet estimate of $0.85 \pm 0.13$. 


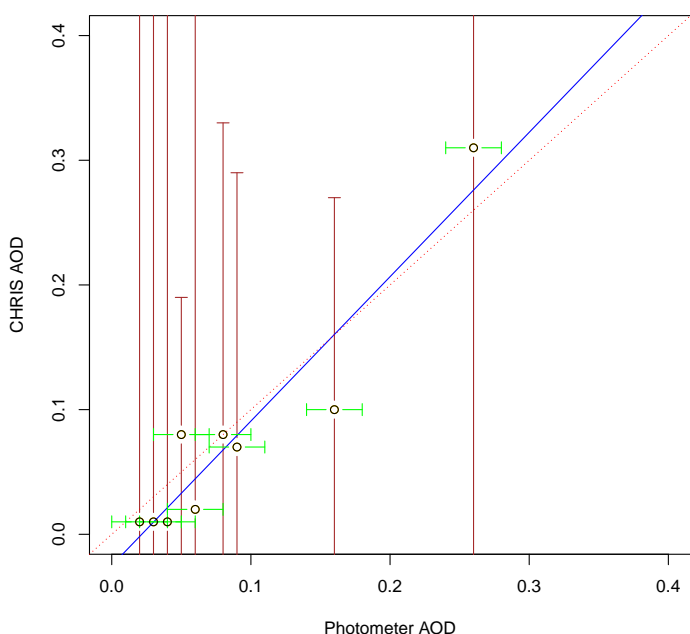

Figure 14. AOD comparison for synergistic retrieval from CHRIS data where the mean NDVI $>0.4$.

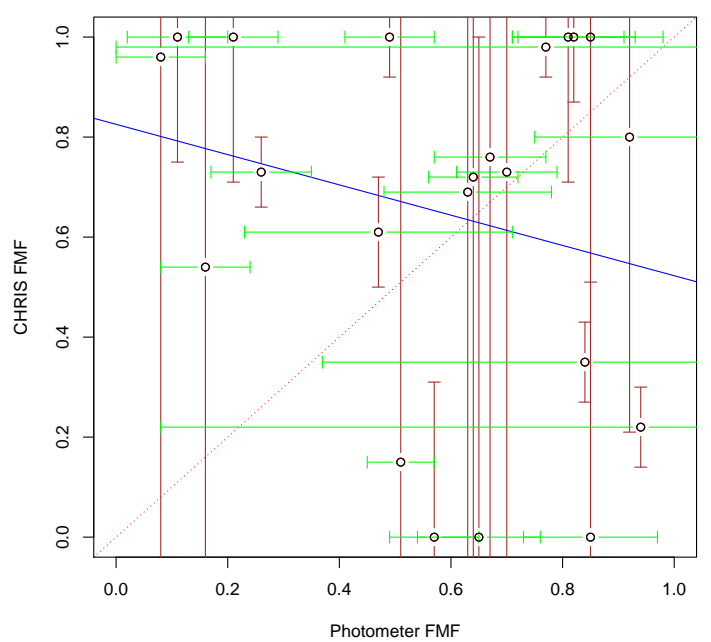

Figure 15. FMF comparison for synergistic retrieval from CHRIS data, over all data points.

\subsection{SSA from CHRIS data}

The SSA value for each of the CHRIS image sets, calculated from the estimated mixture using the synergistic method, is compared with the AERONET estimates in Fig. 16. The numerical results are also listed in Table 7. Thresholding on high NDVI and optical depth yielded only one suitable site with Aeronet data, Mexico City (mc3ae3). Here the satellite retrieval estimated the SSA as $0.95 \pm 0.63$ compared to the Aeronet estimate of $0.77 \pm 0.05$.

\section{Discussion}

The results from the synergistic retrieval of AOD displayed in Fig. 10 show that the method presented in this paper improves over the original method demonstrated for CHRIS

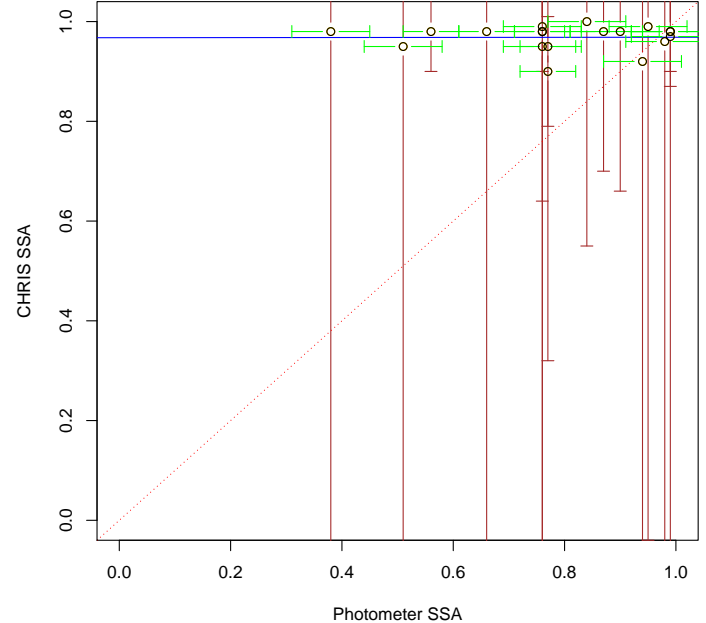

Figure 16. SSA comparison for synergistic retrieval from CHRIS data, over all data points.

PROBA (Fig. 2) (Davies et al., 2010), with an RMSE $\left(r^{2}\right)$ of $0.06(0.65)$ compared to $0.09(0.60)$ for the original method.

The results from the spectral retrieval of AOD displayed in Fig. 8 show that the addition of spectral constraint does not provide useful information over all surface types. However, when the surface types are filtered to only include vegetation where the mean NDVI is greater than 0.4 the results are significantly better as seen in Figs. 9 and 14. This leads to an expectation that the real data will also benefit from filtering out of low NDVI scenes, where the angular constraint alone can provide a retrieval.

The poor results from the retrieval of FMF and SSA on the full data set are consistent with the expectation that the filtering out of both low AOD and low NDVI scenes is required for retrieval of further aerosol properties than AOD. It should also be noted that the lowest possible SSA within the LUT is 0.74 , for $100 \%$ strongly absorbing aerosol, whereas four of the Aeronet estimates of SSA in this data set are below this value, so could not be retrieved. According to Kazadzis et al. (2010), SSA may be the most significant uncertainty in current modelling of aerosol forcing, suggesting greater focus on retrieving this property for future research. While simulation results suggested retrieval of SSA was possible at higher AOD levels, further research is recommended to identify and test CHRIS image sets that have a higher AOD and NDVI and to experiment with different values of refractive index for strongly absorbing aerosols. Finally it should be noted that only a subset of Sentinel-3 spectral bands were available from CHRIS, and improved results are expected by including wavebands beyond $1 \mu \mathrm{m}$. 


\section{Conclusions}

A method for estimating AOD, FMF, and SSA from CHRIS/PROBA-1 images using corresponding Sentinel-3 bands for the spectral retrieval has been developed and tested on 22 image sets from six sites for AOD and FMF and 19 image sets from five sites for SSA. The method retrieves an optimal mix of aerosol components using non-spherical dust, sea salt, weakly absorbing and strongly absorbing aerosol types as end members.

Estimates of AOD from this extended method were compared to the AOD estimates from previous work, using the standard 6S models with one unknown (Davies et al., 2010). The results show an improvement to the previous estimates with an RMSE of 0.06 and $r^{2}$ of 0.65 for the extended method, compared to 0.09 and 0.60 respectively for the previous method. The RMSE is 0.03 for the screened image sets where the mean NDVI is greater than 0.4 and the $r^{2}$ is 0.89 . Testing of the AOD retrieval on a synthetic data set also shows RMSE of 0.03 and an $r^{2}$ of 0.97 , from 560 TOA radiance sets.

For estimation of FMF and SSA, results from simulated data show an RMSE of 0.11 and $r^{2}$ is 0.86 for FMF and an RMSE of 0.02 in SSA with an $r^{2}$ of 0.77 , with results improving at higher optical depth. However, results from CHRIS data over the full data set do not show correlation between retrieved FMF and SSA with Aeronet values. Screened image data did not yield sufficient number of points to reliably test the retrieval of aerosol properties. Further research is therefore recommended to examine the retrieval of aerosol properties over higher AOD values and over vegetated surfaces, and to explore the performance using different models of aerosol properties and surface spectra.

\section{The Supplement related to this article is available online at doi:10.5194/amt-8-1719-2015-supplement.}

Acknowledgements. This work was supported by the NERC National Centre for Earth Observation, and by the European Space Agency. The authors would also like to thank the following: the AERONET principal investigators and their staff for establishing and maintaining the sites used in this investigation; ESA for providing the CHRIS data, and Jeff Settle for discussion of error estimation.

Edited by: O. Torres

\section{References}

Ackerman, A. S., Toon, O. B., Stevens, D. E., Heymsfield, A. J., Ramanathan, V., and Welton, E. J.: Reduction of tropical cloudiness by soot, Science, 288, 1042-1047, 2000.
Baldridge, A. M., Hook, S. J., Grove, C. I., and Rivera, G.: The ASTER spectral library version 2.0, Remote Sens. Environ., 113, 711-715, 2009.

Bergstrom, R. W., Russell, P. B., and Hignett, P.: Wavelength dependence of the absorption of black carbon particles: predictions and results from the TARFOX experiment and implications for the aerosol single scattering albedo, J. Atmos. Sci., 59, 567-577, 2002.

Bevan, S. L., North, P. R., Los, S. O., and Grey, W. M.: A global dataset of atmospheric aerosol optical depth and surface reflectance from AATSR, Remote Sens. Environ., 116, 199-210, 2012.

Cutter, M. A.: CHRIS Data Format, Sira Technology Ltd., Kent, UK, 4.2 edn., 2005.

Cutter, M. A. and Lobb, D. R.: Design of the compact highresolution imaging spectrometer (CHRIS), and future developments, available at: http://envisat.esa.int/pub/ESA_DOC/ PROBA/Sira5thICSO2004CHRISpaperSP-554.PDF (last access: 25 April 2014), 2004.

Davidson, M. and Vuilleumier, P.: Note on CHRIS acquisition procedure and image geometry, available at: http: //earth.esa.int/pub/ESA_DOC/CHRIS_acquisition-procedure_ image-geometry_rev1_3.pdf (last access: 25 April 2014), 2004.

Davies, W. H., North, P. R. J., Grey, W. M. F., and Barnsley, M. J.: Improvements in aerosol optical depth estimation using multiangle CHRIS/PROBA images, IEEE T. Geosci. Remote, 48, 18-24, 2010.

de Leeuw, G., Holzer-Popp, T., Bevan, S. L., Davies, W. H., Descloitres, J., Graigner, R. G., Griesfeller, J., Heckel, A., von Hoyningen Huene, W., Kinne, S., Klüser, L., Kolmonen, P., Litvinov, P., Martynenko, D., North, P. R. J., Ovigneur, B., Poulsen, C. A., Ramon, D., Schulz, M., Siddans, R., Sogacheva, L., Tanré, D., Thomas, G. E., Timo, H., Vountas, M., and Pinnock, S.: Evaluation of seven European aerosol optical depth retrieval algorithms for climate analysis, Remote Sens. Environ., doi:10.1016/j.rse.2013.04.023, online first, 2013.

Diner, D. J., Abdou, W., Ackerman, T. P., Crean, K., Gordon, H. R., Kahn, R. A., Martonchik, J. V., McMuldroch, S., Paradise, S. R., Pinty, B., Verstraete, M. M., Wang, M., and West, R. A.: MISR Level 2 Aerosol Retrieval Algorithm Theoretical Basis, available at: http://eospso.gsfc.nasa.gov/eos_ homepage/for_scientists/atbd/docs/MISR/atbd-misr-09.pdf (last access: 25 April 2014), 2008.

Donlon, C., Berruti, B., Buongiorno, A., Ferreira, M.-H., Féménias, P., Frerick, J., Goryl, P., Klein, U., Laur, H., Mavrocordatos, C., Nieke, J., Rebhan, H., Seitz, B., Stroede, J., and Sciarra, R.: The Global Monitoring for Environment and Security (GMES) Sentinel-3 mission, Remote Sens. Environ., 120, 37-57, 2012.

Dubovik, O., Holben, B. N., Eck, T. F., Smirnov, A., Kaufman, Y. J., King, M. D., Tanré, D., and Slutsker, I.: Variability of absorption and optical properties of key aerosol types observed in worldwide locations, J. Atmos. Sci., 59, 590-608, 2002.

ESA-Archive: CHRIS, available at: https://oa-es.eo.esa.int/ra/ (last access: 20 August 2014), 2014.

ESA-Earth-Online: Sentinel-3, available at: http://earth.esa.int/ web/guest/missions/esa-future-missions/sentinel-3 (last access: 5 March 2014), 2014. 
GCOS, G. C. O. S.: Systematic Observation Requirements for Satellite-based Products for Climate, available at: http: //www.wmo.int/pages/prog/gcos/Publications/gcos-107.pdf (last access: 5 March 2014), 2006

Gómez-Chova, L., Alonso, L., Guanter, L., Camps-Valls, G., Calpe, J., and Moreno, J.: Correction of systematic spatial noise in push-broom hyperspectral sensors: application to CHRIS/PROBA images, Appl. Optics, 47, F46-F60, 2008.

Guanter, L., Alonso, L., and Moreno, J.: A method for the surface reflectance retrieval from PROBA/CHRIS data over land: application to ESA SPARC campaigns, IEEE T. Geosci. Remote, 43, 2908-2917, 2005.

Holzer-Popp, T., de Leeuw, G., Griesfeller, J., Martynenko, D., Klüser, L., Bevan, S., Davies, W., Ducos, F., Deuzé, J. L., Graigner, R. G., Heckel, A., von Hoyningen-Hüne, W., Kolmonen, P., Litvinov, P., North, P., Poulsen, C. A., Ramon, D., Siddans, R., Sogacheva, L., Tanre, D., Thomas, G. E., Vountas, M., Descloitres, J., Griesfeller, J., Kinne, S., Schulz, M., and Pinnock, S.: Aerosol retrieval experiments in the ESA Aerosol_cci project, Atmos. Meas. Tech., 6, 1919-1957, doi:10.5194/amt-61919-2013, 2013.

IPCC: Climate Change 2013: The Physical Science Basis. Contribution of Working Group I to the Fifth Assessment Report of the Intergovernmental Panel on Climate Change, edited by: Stocker, T. F., Qin, D., Plattner, G. K., Tignor, M., Allen, S. K., Boschung, J., Nauels, A., Xia, Y., Bex, V., and Midgley, P. M., Cambridge University Press, Cambridge, UK, New York, NY, USA, 2013.

Kazadzis, S., Gröbner, J., Arola, A., and Amiridis, V.: The effect of the global UV irradiance measurement accuracy on the single scattering albedo retrieval, Atmos. Meas. Tech., 3, 1029-1037, doi:10.5194/amt-3-1029-2010, 2010.

Kokhanovsky, A. A. and DeLeeuw, G.: Satellite Aerosol Remote Sensing over Land, Springer Praxis Books, Heidelberg, 2009.

Kokhanovsky, A. A., Deuzé, J. L., Diner, D. J., Dubovik, O., Ducos, F., Emde, C., Garay, M. J., Grainger, R. G., Heckel, A., Herman, M., Katsev, I. L., Keller, J., Levy, R., North, P. R. J., Prikhach, A. S., Rozanov, V. V., Sayer, A. M., Ota, Y., Tanré, D., Thomas, G. E., and Zege, E. P.: The inter-comparison of major satellite aerosol retrieval algorithms using simulated intensity and polarization characteristics of reflected light, Atmos. Meas. Tech., 3, 909-932, doi:10.5194/amt-3-909-2010, 2010.
North, P. and Heckel, A.: Sentinel-3 L2 Products and Algorithm Definition: SYN Algorithm Theoretical Basis Document S3-L2-SD-03-S02-ATBD, available at: https://earth.esa.int/ documents/247904/349589/SYN_L2-3_ATBD.pdf (last access: 28 May 2014), 2012.

North, P., Brockmann, C., Fischer, J., Gomez-Chova, L., Grey, W., Heckel, A., Moreno, J., Preusker, R., and Regner, P.: MERIS/AATSR synergy algorithms for cloud screening, aerosol retrieval and atmospheric correction, Proc. 2nd MERIS/AATSR User Workshop, ESRIN, Frascati, 22-26, 2008.

North, P., Grey, W., Heckel, A., Fischer, J., Preusker, R., and Brockmann, C.: MERIS/AATSR Synergy: Land Aerosol and Surface Reflectance Algorithm Theoretical Basis Document (ATBD), available at: http://github.com/downloads/bcdev/ beam-meris-aatsr-synergy/synergy-land_aerosol-atbd.pdf (last access: 28 May 2014), 2010.

North, P. R. J.: Estimation of aerosol opacity and land surface bidirectional reflectance from ATSR-2 dual-angle imagery: operational method and validation, J. Geophys. Res., 107, doi:10.1029/2000JD000207, AAC4-1-AAC4-10, 2002.

North, P. R. J., Briggs, S. A., Plummer, S. E., and Settle, J. J.: Retrieval of land surface bidirectional reflectance and aerosol opacity from ATSR-2 multi-angle imagery, IEEE T. Geosci. Remote, 37, 526-537, 1999.

Press, W. H., Teukolsky, S. A., Vetterling, W. T., and Flannery, B. P.: Numerical Recipes in C, The Art of Scientific Computing (Second Edition), Cambridge University Press, Cambridge, 1992.

Vermote, E. F., Tanré, D., Deuzé, J. L., Herman, M., and Morcette, J. J.: Second simulation of the satellite signal in the solar spectrum, 6S: an overview, IEEE T. Geosci. Remote, 35, 675-686, 1997a.

Vermote, E. F., Tanré, D., Deuzé, J. L., Herman, M., and Morcette, J. J.: Second simulation of the satellite signal in the solar spectrum, 6S: Users Guide, Laboratoire d'Optique Atmospherique, U. S. T. de Lille, 59655 Villeneuve d'Aseq, France, 2 edn., 1997b.

von Hoyningen-Huene, W., Yoon, J., Vountas, M., Istomina, L. G., Rohen, G., Dinter, T., Kokhanovsky, A. A., and Burrows, J. P.: Retrieval of spectral aerosol optical thickness over land using ocean color sensors MERIS and SeaWiFS, Atmos. Meas. Tech., 4, 151-171, doi:10.5194/amt-4-151-2011, 2011. 